\title{
Evaluation of the thermography of gingival condition in children and adolescents with insulin- dependent diabetes mellitus (IDDM)
}

\author{
by Dorota Burchardt,Maria Borysewicz-Lewicka, ${ }^{*}$ Mieczysław Walczak
}

\author{
Department of Paediatric Dentistry, Institute of Dentistry,K.Marcinkowski University of Medical \\ Sciences,Poznań,Poland, burchardt@go2.pl \\ ${ }^{\star}$ Department of Endocrinology and Diabetes , Institute of Paediatrics, K.Marcinkowski University \\ of Medical Sciences, Poznań,Poland
}

\begin{abstract}
Patients diagnosed with periodonthopathies were subjected to thermographic study in order to analyse blood circulation in the periodontal region and pattern of temperature changes in the gingival crevices.

The aim of the study was to assess the influence of insulin-dependent diabetes mellitus (IDDM) on the status of blood vessels in the periodontal region in children and adolescents.

Clinical status of the periodontal region was assessed with CPITN (Community Periodontal Index of Treatment Needs).

Thermographic patterns were taken in the vicinity of teeth 11 and 21 at some distance from the gingival margin and frenulum of the upper lip, which permitted elimination of a possible influence of other factors on the parameters studied. The thermographic measurements were a few times repeated for each patient and made before and 1,2,3, and 4 minutes after cooling of a selected surface of gingival mucosa. Interpretation of the thermographic patterns was performed taking into account the minimum and maximum temperatures: $T$ min and $T$ max, and $T x-$ the weighted mean for the left and right sides.

Preliminary observations revealed a difference between the data obtained in the group with IDDM and the control group. The results suggest the suitability of the thermographic study for assessment of vascular changes in IDDM patients.
\end{abstract}

\section{Introduction}

Thermography is a non-invasive method allowing evaluation of the temperature changes on the surface of the skin or mucous, which reflect the presence of inflammatory process. The method also permits indirect monitoring of blood circulation in small and large vessels $[13,14]$.

In dentistry thermography has been often used for investigation of tissues, e.g. in maxillary facial oncology, diagnostics of temporo-mandibular joint, parotid gland, periodontal changes, inflammatory states of maxillary sinus, in evaluation of effectiveness of endodontic treatment, performance of implants and influence of lasers on dental pulp $[1,2,3,5,6,7,8,9,10,11,12]$.

IDDM development leads to chronic hyperglicaemia, which may produce different complications. One of the conditions it may produce is diabetic microangipathy most markedly manifested in retina, kidneys, peripheral nerves and in the periodontal region. The appearance of the complications is related to chronic metabolic decompensation reflected by the elevated values of $\mathrm{HbA}>9.5 \%$ and level of fructosamine $>3.7 \mathrm{mmol} / \mathrm{l}$. In patients with IDDM thermography has been most often used in diagnostics of the so-called diabetic foot [4]. 


\section{The aim of study}

The aim of the study is to perform the thermographic assessment of the status of gingiva in children and adolescents with long-lasting and decompensated diabetes.

\section{Material and methods}

Thermographic study of the periodontal region was performed in 32 IDDM patients:

12 boys aged $10-19(x=16.4)$

20 girls aged 11-19 ( $x=15.0)$.

The time of IDDM condition was:

$4-13$ years $(x=6.6)$ in the group of boys

4-14 years $(x=7.0)$ in the group of girls.

The indices of metabolic decompensation taking mean values of HbA1 11.9\%

and fructosamine level of $4.72 \mathrm{mmol} / \mathrm{l}$, indicated decompensation.

The status of the periodontal region was described by CTIPN. Clinical examination of the oral cavities took place in a dental surgery using a mirror and a periodontal probe (WHO-621).

Thermographic measurements were made by using AGA Thermovision System 680 thermograph (AGA AKTIEBOLAG Infrared Instruments Department, Sweden) allowing contactless reproduction of temperature of oral cavity mucosa. The measurements were performed when the patient was sitting with the head stabilised in a holder, using a standard lip expander and a temperature reference to calibrate the camera.

The mean body temperature of the patients and the control group members was $36.6^{\circ} \mathrm{C}$, and the mean ambient temperature was $23^{\circ} \mathrm{C}$. Variations of these temperatures in both groups were statistically insignificant ( $p>0.05)$.

The measurements were made in the vicinity of teeth 11 and 21[Fig. 1] all teeth studied were with alive dental pulp. Having taken the first steady thermogram, the patient was asked to rinse the oral cavity with water mixed with ice (temp. $2^{\circ} \mathrm{C}$ ) for 60 seconds, and subsequent thermograms were recorded after 1, 2, 3 and 4 minutes. For each patient the values of Tmin, Tmax and Tx-the weighted mean were found from each thermogram (taking into account the arithmetic means for particular isotherms). A similar study was performed in 18 healthy subjects from the control group including 10 girls of the mean age 17.0 and 8 boys of the mean age 16.9. Medians were calculated for each group.

\section{Results}

On the basis of the clinical studies the percent of subjects with healthy periodontal region among the IDDM patients was $9.4 \%$, while in the control group it was $35.0 \%$ (kod0). The inflammatory changes in the periodontal region were much more advanced in the group of patients with IDDM [Fig. 2].

Statistical analysis of the thermographic patterns (Wilcoxon's test) did not reveal statistically significant changes between the temperatures for the left and right sides $(p>0.05)$, which is consistent with literature data [11].

A comparison of the mean values (Me) of temperatures for the left and right sides in the group of IDDM patients and the control group, higher values were found in the former [Fig.3,4]. This fact may be interpreted as indicating more advanced inflammatory changes in gingiva of IDDM patients.

Statistically significant differences (Mann-Whitney's test) were found between particular temperatures measured at times T0 $(p<0.01), T 2(p<0.05), T 3(p<0.05), T 4(p<0.05)$. The difference between the temperatures measured at $\mathrm{T} 1(\mathrm{p}>0.05)$ was statistically insignificant for both groups, which can be related to the effect of cooling which reduced the temperature of the tissues studied to the same degree. 


\section{Conclusions}

1. More advanced changes in the periodontal region are observed in children and adolescents with long lasting IDDM of decompensated character.

2. The temperature of gingival tissues in IDDM sufferers is higher than in the healthy subjects, which suggests the suitability of the thermographic study to assess vascular changes.

\section{References}

[1]BARNETT M.L.,GILMAN R.M.et al."Computer - Based Thermal Imaging of Human Gingiva",J.Periodontol 1989;60;628-633

[2]CHAIRAY J.-P.,DELCOURT -DEBRUYNE E.,FLAMENT G.,"Apport de la thermographie dans l'evaluation clinique et therapeutique des parodontopathies",

Actualitès Odonto-Stomatologique,1981;136;665-673

[3] CRAIG B.SOFFIN et al. ."Thermography and oral inflammatory conditions", Oral Surg;1983;56;3;256-262

[4]HARDING J.R.,WERTHEIM D.F.et al.,"Infrared Imaging in Diabetic Foot Ulceration", European Journal of Thermology,1998;8/4;145-149;

[5]HOLTHUIS A.F.,CHEBIB F.S.,"Observations on Temperature and Temperature Patterns of the Gingiva",J.Periodontol;1983;54;10;624-628

[6]HUSSEY DL,BIAGIONI PA,et al. ."Thermographic assessment of heat generated on the root surface during post space preparation",Int Endod J;1997,May;30(3):187-90

[7]KAPLAN M.L.et al. ."Blood flow in gingiva and alveolar bone in beagles with periodontal disease",Journal of Periodontal Research;1982;17;384-389

[8]McCULLAGH JJ,BIAGIONI PA et al. ."Thermographic assessment of root canal obturation using thermomechanical compaction",Int Endod J;1997:May:30(3):191-5

[9]McCULLAGH P,SETCHELL DJ,et al. ."Infrared thermographic analysis of temperature rise on implant surfaces:a pilot study on abutment preparation",

Pract Periodontics Aesthet Dent;1998;Nov-Dec;10(9);1163-1167

[10]MELNIZKY P.,SCHARTELMüLLER T.,"Thermographie bei Sinusitis-Patienten", Thermology International (abstract) 1999;9/1;30

[11] MöRMANN W.H.et al. „The thermodynamic behavior of labial gingiva in patients with destructive periodontal disease".,Journal of Clinical Periodontology,1985;12;477-493

[12]SCHINDL A,SCHINDL M,et al. "Low-intensity laser irradiation improves skin circulation in patients with diabetic microangiopathy",Diabetes Care ,1998;21/4;580-584

[13]WIECEK B,"New trends in dynamic thermography „European Journal of Thermology, 1998;8;129;

[14]ŻUBER J.,JUNG A.,"Metody termograficzne w diagnostyce medycznej",Wydawnictwo BAMAR,Warszawa,1997; 


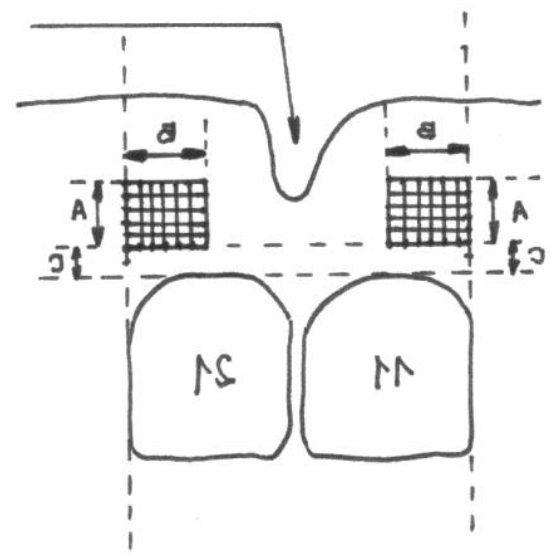

frenulum of the upper lip

A- 5 pixels

B-6 pixels

C-2 pixels

Figure1.Schematic presentation of the periodontal region examined

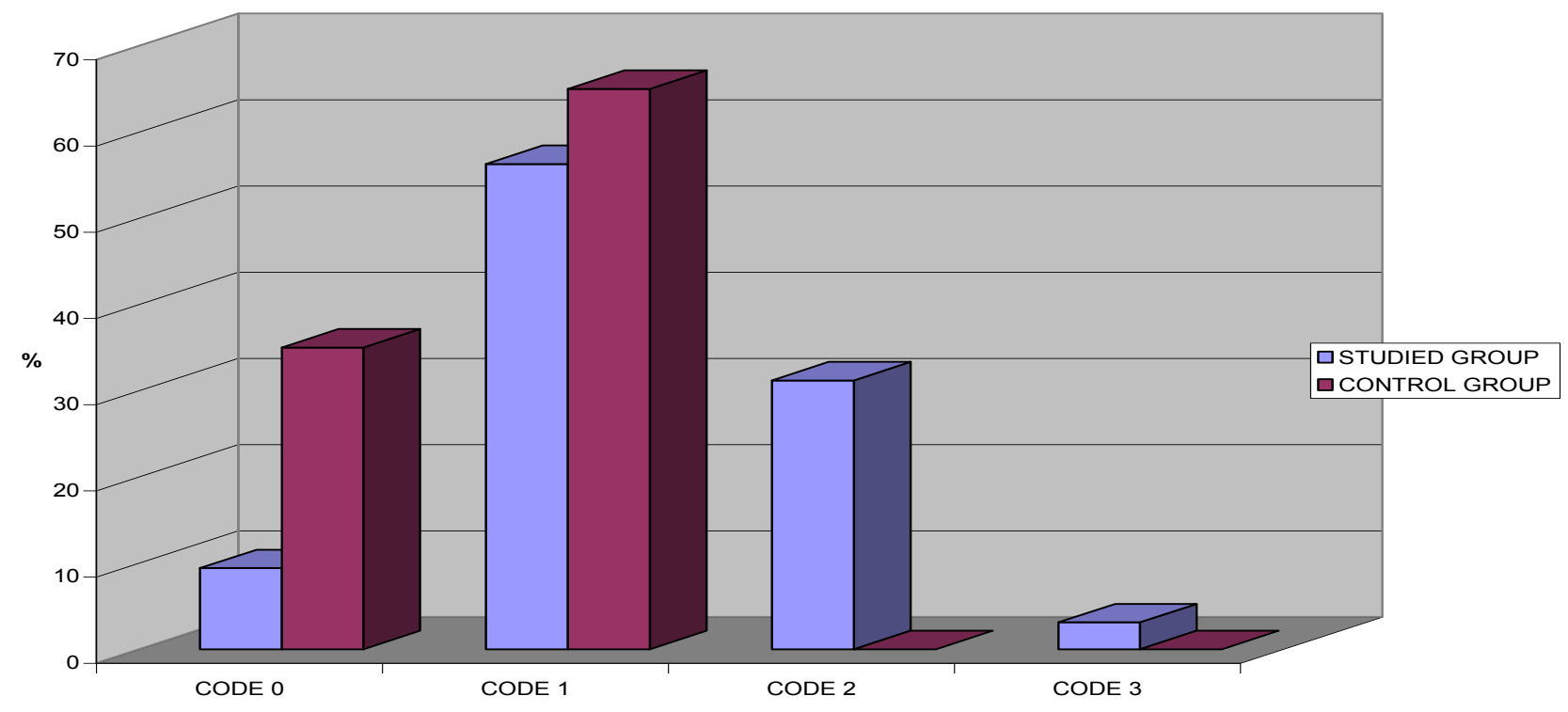

Figure 2.Pecent of subjects with different periodontal status (codes 0-3)

with the maximum CPITN value:

code 0-healthy periodontal region

code 1-bleeding on probing

code 2-bleeding on probing,over- and under-dental calculus at the gingival pocket depth greater than $3 \mathrm{~mm}$

code 3- bleeding on probing,over- and under-dental calculus at the gingival pocket depth 4,0-5,5 mm 
http://dx.doi.org/10.21611/qirt.2000.002

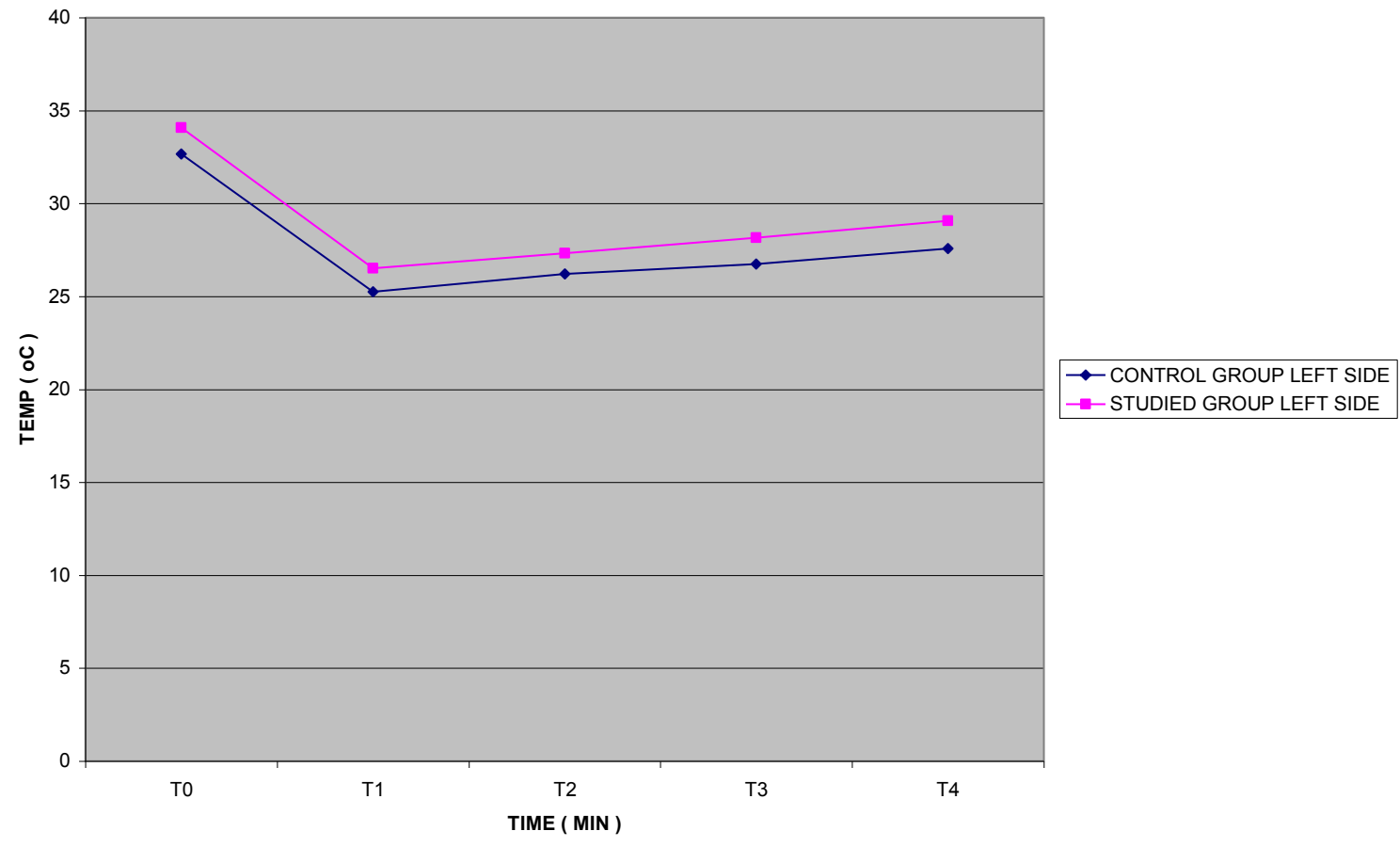

Figure 3.Mean temperature values (Me-median) obtained for measurement at particular moments for the left side of the body

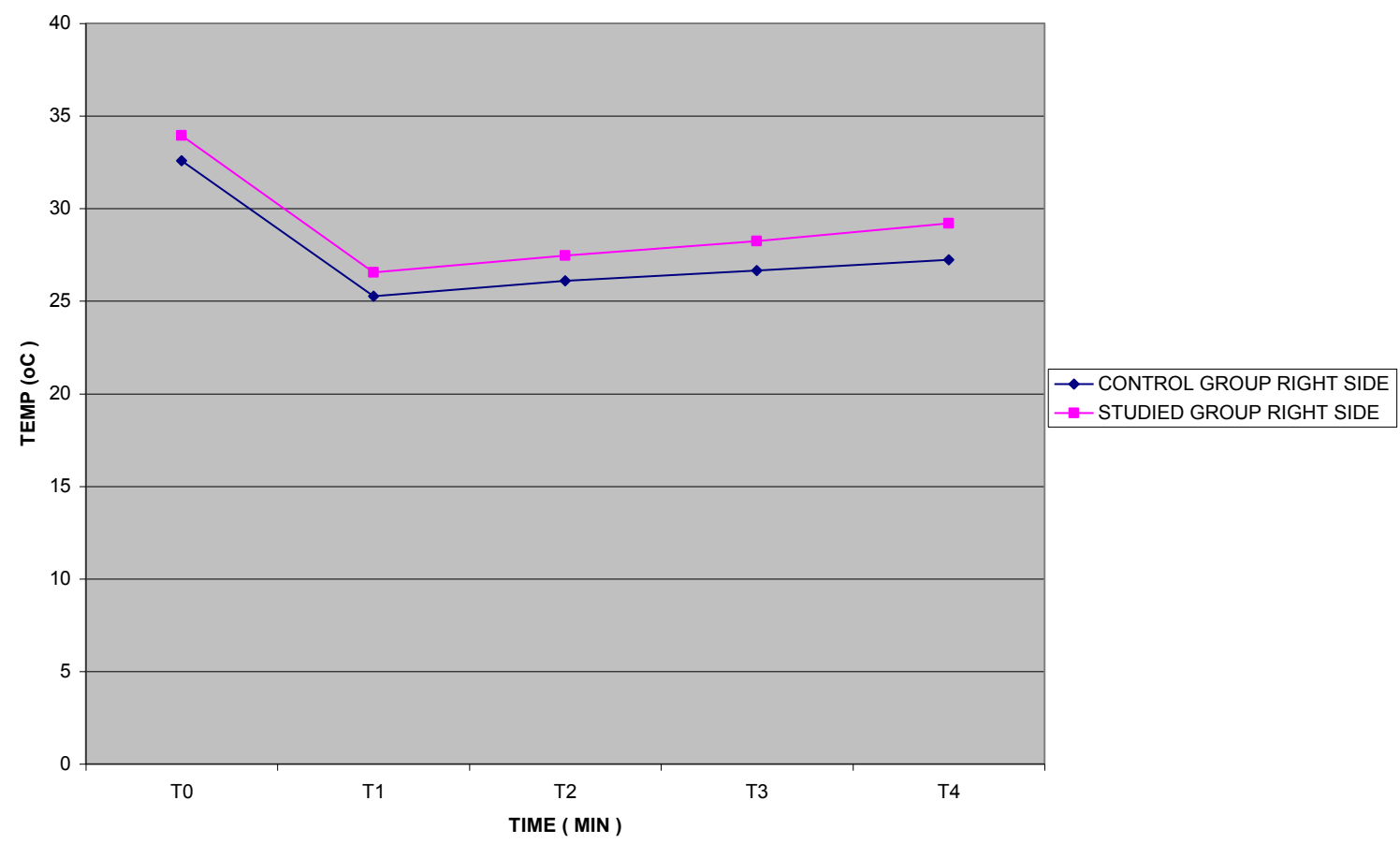

Figure 4.Mean temperature values (Me-median) obtained for measurement at particular moments for the right side of the body 